\title{
Correlations between SARA Fractions, Density, and RI to Investigate the Stability of Asphaltene
}

\begin{abstract}
Ali Chamkalani
Department of Petroleum Engineering, Petroleum University of Technology, P.O. Box 63431, Ahwaz, Iran

Correspondence should be addressed to Ali Chamkalani, alicham179@gmail.com

Received 24 September 2011; Accepted 24 October 2011

Academic Editors: T. C. Dinadayalane, A. M. Farag, and N. Fujita

Copyright () 2012 Ali Chamkalani. This is an open access article distributed under the Creative Commons Attribution License, which permits unrestricted use, distribution, and reproduction in any medium, provided the original work is properly cited.

Asphaltene precipitation is one of the most common problems in both oil recovery and refinery processes. Its deposition causes many problems mainly because of the fuzzy nature of asphaltene and the large number of parameters affecting precipitation. Unfortunately there is not a predictive technique for screening it. Refractive index (RI) was used as a stability test for asphaltene which makes a quantitative judgment for asphaltene stability. In our study, we first represent a novel correlation between SARA fractions and density and then demonstrate the relation between density and RI; second we developed a relation for SARA and RI, by utilizing RI to investigate the stability of asphaltene.
\end{abstract}

\section{Introduction}

Asphaltene deposition in oil reservoirs and/or production facilities causes a remarkable reduction of formation productivity/injectivity. Many literatures [1-3] gave the description of asphaltene problems and remedies throughout the world. Although asphaltene precipitation is a worldwide problem, its main cause has not been completely under stood [4]. The mechanism of asphaltene precipitation is very complex, despite a wealth of research on the topic. Controversy remains as to the nature of solving this problem [5]. According to the field experience $[6,7]$ and experimental observations [8-11], asphaltene stability depends on a number of factors, including the composition of the surrounding fluid, pressure, and temperature, in which asphaltene solubility is highly dependent on the composition of the crude, less dependent on the pressure, and hardly dependent on temperature.

\section{Asphaltene Deposition Models}

Effort has been done to present a universal model for asphaltene deposition. The existing models for asphaltene precipitation fall into three classes: (I) molecular thermodynamic models in which asphaltenes are dissolved in crude oil and crude oil forms a real solution [12-15]; (II) colloidal models in which asphaltene is suspended in crude oil and peptized by resins. The asphaltene precipitation is irreversible in such models [16-18]. Reversibility experiments are strongly against this type of models; (III) models based on scaling equation in which the properties of complex asphaltenes are not involved $[19,20]$.

\section{Screening Technique for Asphaltene Stability}

SARA analysis began with the work of Jewell et al. [21]. The saturate fraction consists of nonpolar material including linear, branched, and cyclic saturated hydrocarbons. Aromatics, which contain one or more aromatic rings, are more polarizable. The remaining two fractions, resins and asphaltenes, have polar substituents. The distinction between the two is that asphaltenes are insoluble in an excess of heptane (or pentane) whereas resins are miscible with heptane (or pentane) [22-24]. Resins are structural similar to asphaltenes, but smaller in molecular weight $(<1000 \mathrm{~g} / \mathrm{mole})$ [24].

The proportions of each of the SARA fractions in a crude oil are related to the stability of asphaltenes in that oil. Resins have a strong tendency to associate with asphaltenes. Such association determines, to a large extent, 
their solubility in crude oil [25] in which resin molecules react at the addition of the light paraffin components by desorbing from the asphaltenes in an attempt to reestablish thermodynamic equilibrium, thus increasing the probability of asphaltene self-aggregation. Carbognani and Espidel [26] demonstrated that reservoirs with asphaltene problems were not primarily those with large amounts of asphaltene in the oil, but those with high saturate fractions. Leontaritis and Mansoori [17] recommended using the ratio of resins to asphaltenes as an indicator of asphaltene stability, based on the hypothesis that resins confer asphaltene stability by peptizing (or coating) asphaltenes. Fan et al. [27] observed that the proportions of each of the SARA fractions in a crude oil are related to the stability of asphaltenes in that oil. Alkafeef et al. [28] define the stability of a colloid dispersion as its resistance to flocculation, and the degree of "resistance" is used as a measure of the dispersion stability. Alkafeef et al. [29] point out that the destabilization (i.e., flocculation) of colloidal asphaltenes in oil-production flowing systems depends principally on breaking up the balances of attraction forces between the absorbed resin molecules and asphaltenes particles. De Boer and Leeriooyer [30] proposed a plot that can be used as a first screening tool to identify the potential for the oil to exhibit solid formation problems with having initial pressure, bubble point pressure, reservoir fluid density, and plotting pressure difference versus oil density. Jamaluddin et al. [31] proposed a screening criterion, based on the asphaltene weight percent versus resin weight percent. The colloidal instability index (CII) is another screening criterion, suggested by Yen et al. [32] that can be used to identify crude oil systems with deposit problems. The colloidal instability index is expressed as the ratio of the sum of asphaltenes and saturates to the sum of aromatics and resins. An asphaltene stability index was developed by Jamaluddin et al. [31] that utilized oil density at initial reservoir pressure and at bubble point pressure. Vargas et al. [33] developed a general method for modeling asphaltene stability as making relationships and obtaining a curve between the solubility parameters, cohesive energy, pressure, and composition along the bubble point and onset of asphaltene precipitation.

\section{Refractive Index}

The refractive index (RI) is the degree to which light bends (refraction) when passing through a medium. Values of RI can be measured very accurately and are used to correlate density and other properties of hydrocarbons with high reliability [34]. Information obtained from RI measurements can be applied for various reservoir engineering calculations. The examples are PVT behavior and surface tension of reservoir fluids [34], wetting alterations in reservoirs [35, 36], and asphaltene precipitation [37-39]. The refractive index of light crude oils can be directly measured using conventional refractometer $[35,36,38]$. However, direct measurements of the refractive index of many crudes, natural bitumen, and heavy fuels are unattainable since these liquids are too opaque so RI is only measured for fairly dilute solution; in these cases RI is determined for a series of oil/solvent mixtures and the results are extrapolated (in an assumption of a certain mixing rule) to determine the value for the crude oil $[35,37,40]$. It is usually assumed that a solution of a crude oil (bitumen) behaves as an ideal binary mixture of the components [37-39].

Solubility and RI have been related by the following formula [39]:

$$
\delta=\left(\frac{\sqrt{3} \pi}{384} \frac{h v_{e}}{\sigma^{3}}\right)^{1 / 2} \frac{\sigma^{3}}{V / N_{o}} \frac{n^{2}-1}{\left(n^{2}+2\right)^{3 / 4}},
$$

where $\delta$ is the solubility; $h$ Planck's constant; $V$ the molar volume; $\sigma$ hard sphere diameter; $v_{e}$ absorption frequency in the UV; $N_{o}$ Avogadro's number; $n$ refractive index.

The solubility parameter mapping of Wiehe [41] shows that asphaltene insolubility is dominated by aromaticity and molecular weight, not by polar or hydrogen bonding interactions. Studies at ambient conditions by Wand et al. [42] have shown that the refractive index at the onset of precipitation (PRI) is an important characteristic of oil/ precipitant mixtures.

The aromatic fraction has little or no influence on $\mathrm{RI}_{\text {oil }}$, whereas saturates correlate negatively and the resins and asphaltenes are positively correlated with $\mathrm{RI}_{\text {oil }}$ [27]. Generally speaking, anything that decreases the maltene RI also decreases asphaltene stability. An exception is the effect of increasing temperature, which causes thermal disaggregation even though RI decreases.

The refractive index is expressed as a function of composition and density through the Clausius-Mossotti or Lorenz-Lorentz equation $[43,44]$ in which the validity of the Lorenz-Lorentz equation to describe the density dependence of RI was investigated by Vedam and Limsuwan [44].

As reported previously [45], addition of aromatic or other hydrocarbon solvents has minimal effect on PRI. The fractions of various components in the mixture vary, concentration of the asphaltene fraction, and ratio of precipitant to solvent all vary, but the RI at the onset of precipitation is constant. In mixtures containing precipitate, do not deviate appreciably from the linear relationship between RI and volume fraction of crude oil in the oil-heptane mixture. Deviations of experimental data from "ideal" values are due to mixture containing precipitate component.

\section{Fan et al.'s Method [27]}

Fan and his coworkers related the refractive index of oil, $(\mathrm{RI})_{\text {oil }}$, to the SARA fraction by the following empirical equation:

$$
\begin{aligned}
(\mathrm{RI})_{\mathrm{oil}}= & 0.001452 \times \mathrm{S}+0.0014982 \\
& \times \mathrm{A}+0.0016624 \times(R+\mathrm{As}),
\end{aligned}
$$

where $\mathrm{S}$ is Saturate, A is aromatic, $R$ is resin and AS is asphaltene percent. Fan et al. [27] defined PRI as the refractive index at the onset asphaltene precipitation and proposed that the difference between the refractive index of the oil $(\mathrm{RI})_{\text {oil }}$ 


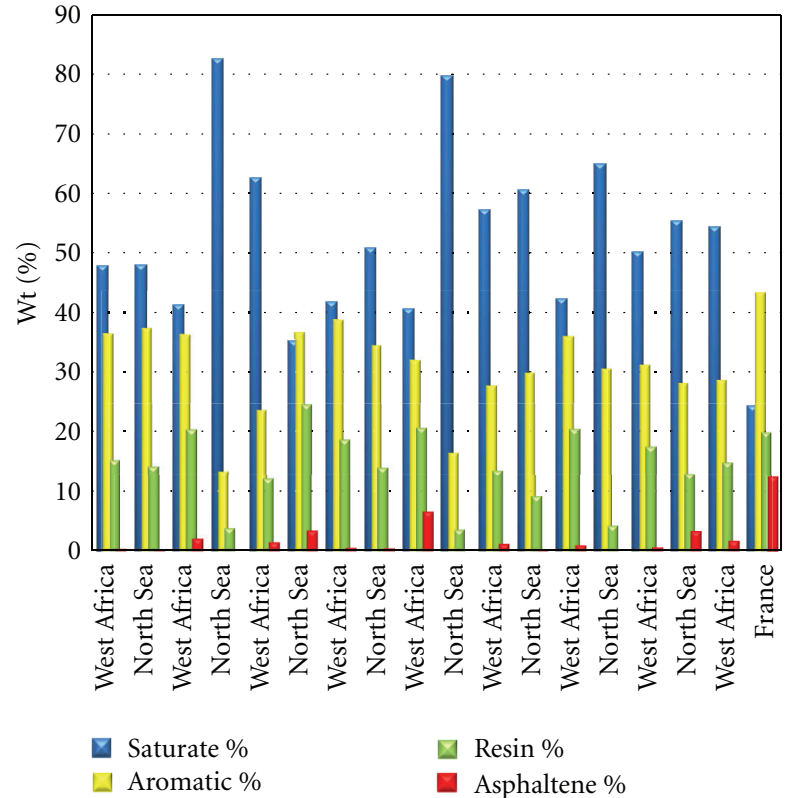

FIGURE 1: SARA percent weight for different fields.

and PRI can be used as a measure of the asphaltene stability, defined

$$
\Delta(\mathrm{RI})=(\mathrm{RI})_{\text {oil }} \times \mathrm{PRI} .
$$

And proposed the following stability criteria:

(i) crude oil with $\Delta(\mathrm{RI})>0.060$ are more likely to have stable asphaltenes;

(ii) crude oil with $\Delta(\mathrm{RI})<0.045$ are more likely to have asphaltene deposit problems;

(iii) crude oil with $0.045<\Delta$ (RI) $<0.060$ are in the border region.

\section{Model Performance}

For evaluation of proposed models, statistical indicators are usually applied to analyze models which are expressed as:

$$
R^{2}=1-\frac{\sum_{i=1}^{n}\left(y_{i_{\text {observed }}}-y_{i_{\text {calculated }}}\right)^{2}}{\sum_{i=1}^{n}\left(y_{i_{\text {observed }}}-\bar{y}\right)^{2}} .
$$

Average relative error:

$$
\operatorname{ARE}=\frac{1}{n} \sum_{i=1}^{n}\left(\frac{y_{i_{\text {calculated }}}-y_{i_{\text {observed }}}}{y_{i_{\text {observed }}}}\right) .
$$

Average absolute relative error:

$$
\mathrm{AARE}=\frac{1}{n} \sum_{i=1}^{n}\left|\frac{y_{i_{\text {callualted }}}-y_{i_{\text {observed }}}}{y_{i_{\text {observed }}}}\right|_{i} .
$$

Standard deviation:

$$
\mathrm{SD}=\sqrt{\left(\frac{1}{n-1}\right) \sum_{i=1}^{n}\left(\frac{y_{i_{\text {calculated }}-y_{i_{\text {observed }}}} y_{i_{\text {observed }}}}{2},\right.},
$$

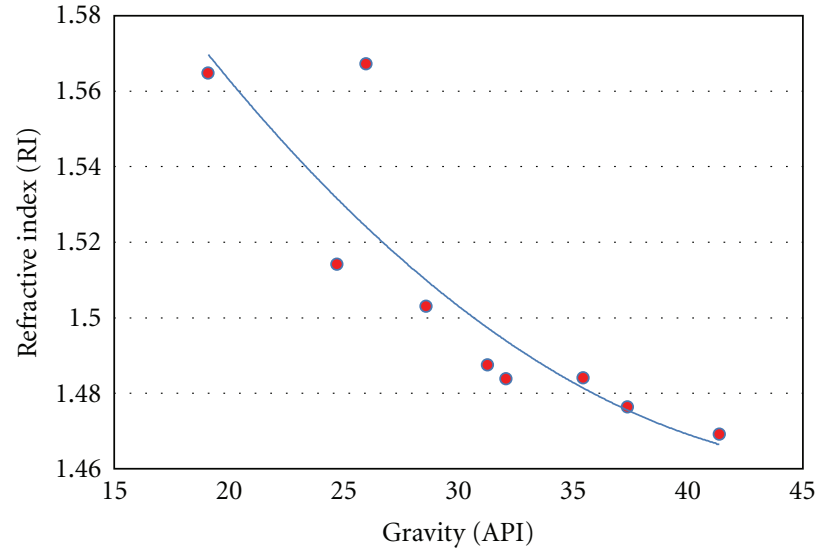

FIgure 2: As API increases, the refractive index decreases.

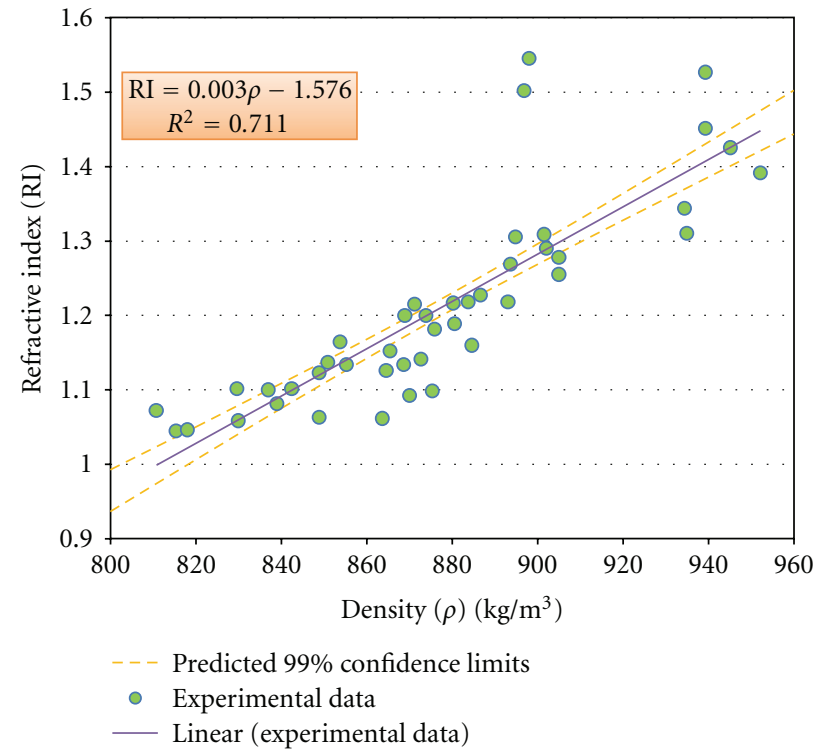

Figure 3: The linear relationship between RI and density with confidence limit of $99 \%$.

where $y_{i_{\text {observed }}}$ is the actual value, $y_{i_{\text {calculated }}}$ is the predicted value of $y$, and $\bar{y}$ is the mean of the data values as in the abovepresented formula.

\section{Results and Discussion}

SARA and density data for SARA-density relation are derived from previous works $[27,46]$. SARA fractions are plotted in Figure 1, and the relation between SARA fraction and density was derived as follows:

$$
\begin{aligned}
\rho= & 0.1402635 \times \mathrm{S}+0.1390173 \times \mathrm{A}+0.1655588 \\
& \times R^{0.9731603}+0.1014975 \times \mathrm{AS}^{1.121967}-13.26466,
\end{aligned}
$$

where $\mathrm{S}$ is saturate, $\mathrm{A}$ is aromatic, $R$ is resin, and AS is asphaltene percent. Related statistical indicators are shown in Table 1 that represents the precision of correlation. 


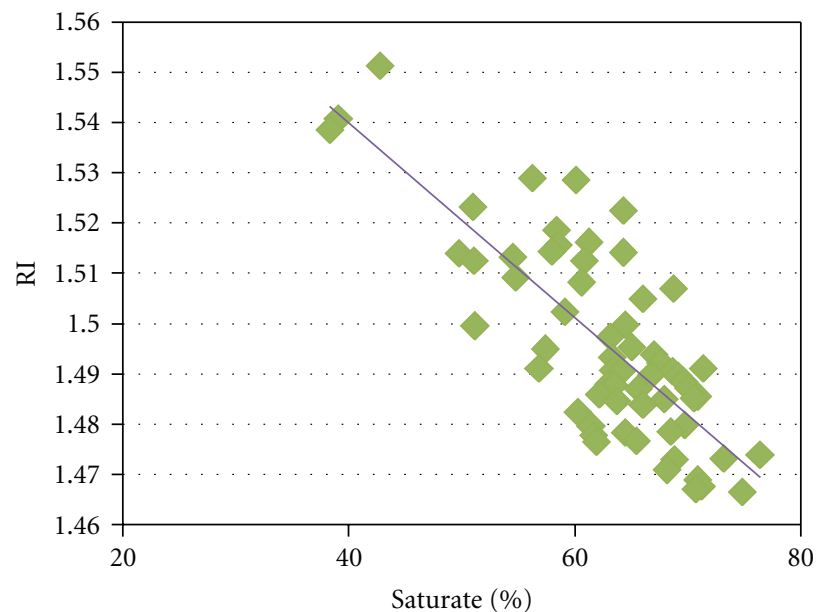

(a)

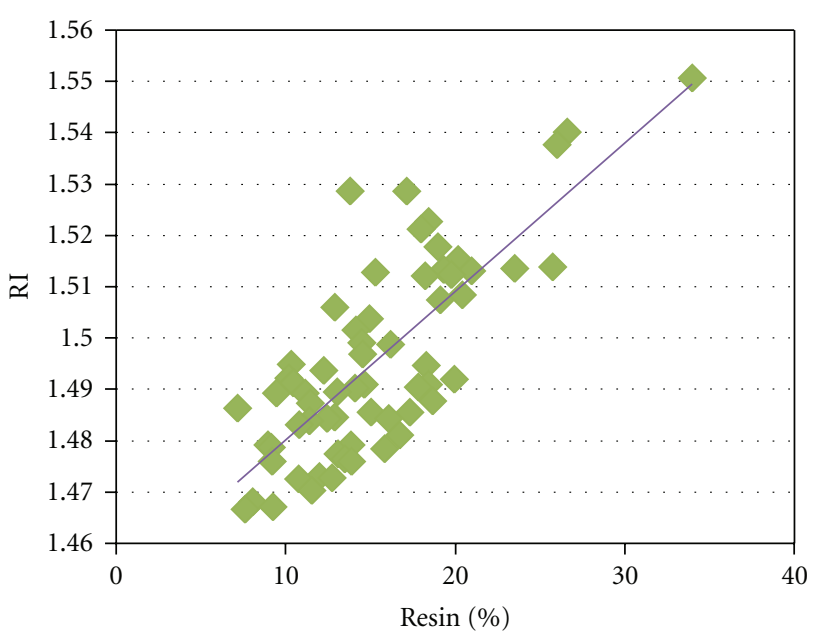

(c)

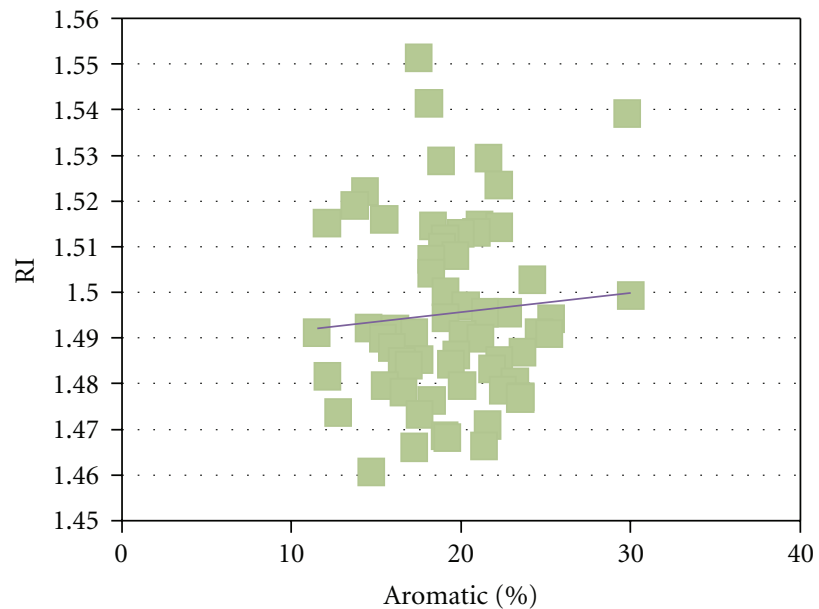

(b)

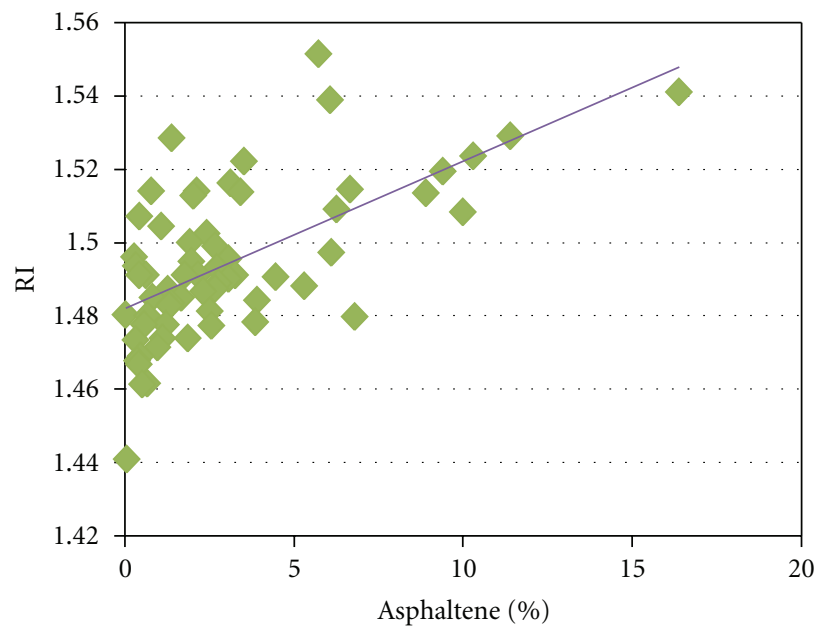

(d)

FIgURE 4: The behavior of RI with change of each fraction of SARA, the negative effect of saturate is apparent.

TABLE 1: Statistical indicators for considering the performance and precision of correlations.

\begin{tabular}{lcccc}
\hline Correlation & $R^{2}$ & ARE & AARE & SD \\
\hline SARA-density & 0.951 & 0.000125 & 0.009055 & 0.010999 \\
RI-density & 0.771 & -0.125557 & 0.125557 & 0.133987 \\
$\begin{array}{l}\text { RI-SARA } \\
\text { (Fan et al.) }\end{array}$ & 0.686 & -0.000139 & 0.006419 & 0.007698 \\
$\begin{array}{l}\text { RI-SARA } \\
\text { (proposed) }\end{array}$ & 0.727 & -0.000047 & 0.005752 & 0.006843 \\
\hline
\end{tabular}

In this paper, it is also demonstrated that, according to relation between density and $\mathrm{API}^{\circ}$, whenever $\mathrm{API}^{\circ}$ increases, the RI decreases (Figure 2), then the data for density and RI were plotted versus each other with a confidence limit of $99 \%$, the present experiment shows that this relationship is linear (Figure 3) which with having density RI could be predicted:

$$
\mathrm{RI}=0.003 \rho-1.576 .
$$

The related correlation precision indicators are pointed in Table 1. Finally we presented a relation between SARA fraction and RI development and obtained a new correlation which, in addition to demonstrating the negative effect of saturate (Figure 4), shows better precision to obtain more accurate RI than what Fan et al. proposed. The proposed correlation by this paper is

$$
\begin{aligned}
\mathrm{RI}=- & -0.0008515 \times \mathrm{S}-0.0002524 \times \mathrm{A}+0.0016341 \\
& \times R+0.0013928 \times \mathrm{AS}+1.524412 .
\end{aligned}
$$

In Figures 5 and 6, obtained RI from Fan et al. and our correlation have been plotted versus observed RI; their accuracy comparison is presented in Table 1 . By using $\Delta(\mathrm{RI})$ asphaltene stability could be investigated.

\section{Conclusion}

In this paper, we investigate relations between SARA fractions and density, between density and RI, and finally 


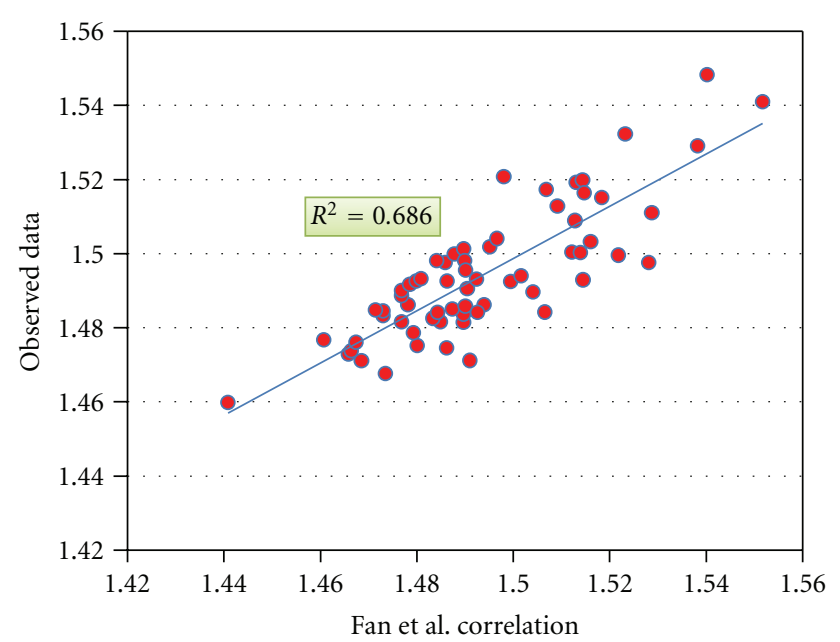

FIgURE 5: The calculated RI with Fan et al.'s correlation versus observed RI.

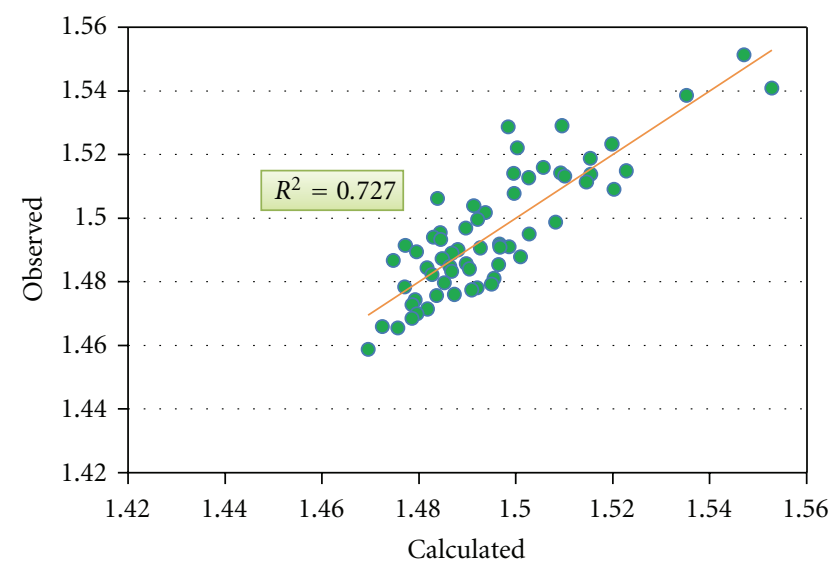

Figure 6: The calculated RI from proposed correlation versus observed RI.

between SARA fractions and RI. As an effort for screening asphaltene deposition is done, the obtained relations show satisfactory results and open new ways to determine RI from density and subsequently diagnosing asphaltene instability for causing problem. Also a comparison between current and previous works for SARA-RI relation has been performed which shows the better accuracy of our model.

\section{Abbreviations}

$\delta: \quad$ Solubility parameter

$v_{e}: \quad$ Absorption frequency in the UV

$N_{o}: \quad$ Avogadro's number

$\sigma: \quad$ Hard sphere diameter

A: Aromatic

AS: Asphaltene

CII: Colloidal stability index

g/mole: Gram per mole

$\mathrm{API}^{\circ}$ : American Petroleum Institute

h: $\quad$ Planck's constant $n$ : $\quad$ Refractive index

PRI: Refractive index at onset point

$R: \quad$ Resin

RI: Refractive index

$\mathrm{RI}_{\mathrm{oil}}$ : Refractive index of oil

S: $\quad$ Saturate

SARA: Saturate, aromatic, resin, asphaltene

$V: \quad$ Molar volume

$\rho: \quad$ Density.

\section{References}

[1] K. J. Leontaritis and G. Ali Mansoori, "Asphaltene deposition: a survey of field experiences and research approaches," Journal of Petroleum Science and Engineering, vol. 1, no. 3, pp. 229-239, 1988.

[2] K. K. Leontaritis, J. O. Amacfule, and R. E. Charles, "A systematic approach for the prevention and treatment of formation damage caused by asphaltene deposition," in Proceedings of the SPE International Symposium and Exhibition on Formation Damage, SPE 23810, Lafayette, La, USA, 1992.

[3] R. Thawer, D. C. A. Nicoll, and G. Dick, "Asphaltene deposition in production facilities," SPE Production Engineering, vol. 5, no. 4, pp. 475-480, 1990.

[4] H. Pan and A. Firoozabadi, "Thermodynamic micellization model for asphaltene precipitation: part I: micellar size and growth," in Proceedings of the Annual Technical Conference and Exhibition, SPE 36741, pp. 593-605, October 1996.

[5] S. I. Andersen and J. G. Speight, "Thermodynamic models for asphaltene solubility and precipitation," Journal of Petroleum Science and Engineering, vol. 22, no. 1-3, pp. 53-66, 1999.

[6] R. B. de Boer, K. Leerlooyer, M. R. P. Eigner, and A. R. D. van Bergen, "Screening of crude oils for asphalt precipitation: theory, practice, and the selection of inhibitors," SPE Production and Facilities, vol. 10, no. 1, pp. 55-61, 1995.

[7] S. L. Kokal and S. G. Sayegh, "Asphaltenes: the cholesterol of petroleum," in Proceedings of the 9th Middle East Oil Show, SPE 29787, Bharain, March 1995.

[8] S. I. Andersen, "Dissolution of solid boscan asphaltenes in mixed solvents," Fuel Science and Technology International, vol. 12, p. 51, 1994.

[9] P. Fotland, H. Anfinsen, H. Foerdedal, and H. P. Hjermstad, "The phase diagrams of asphaltenes: experimental technique, results and modeling on some north sea crude oils," in Proceedings of the Symposium on the Chemistry of the Asphaltene and Related Substances, Cancun, Mexico, 1997.

[10] A. Hammami, C. H. Phelps, T. Monger-McClure, and T. M. Little, "Asphaltene precipitation from live oils: an experimental investigation of onset conditions and reversibility," Energy and Fuels, vol. 14, no. 1, pp. 14-18, 2000.

[11] F. B. Thomas, D. B. Bennion, D. W. Bennion, and B. E. Hunter, "Experimental and theoretical studies of solids precipitation from reservoir fluid," Journal of Canadian Petroleum Technology, vol. 31, p. 22, 1992.

[12] N. E. Burke, R. E. Hobbs, and S. F. Kashou, "Measurement and modeling of asphaltene precipitation," Journal of Petroleum Technology, vol. 42, no. 11, pp. 1440-1446, 1990.

[13] S. Kawanaka, S. J. Park, and G. A. Mansoorl, "Organic deposition from reservoir fluids: a thermodynamic predictive technique," SPE Reservoir Engineering, vol. 6, no. 2, pp. 185192, 1991.

[14] R. Cimino, S. Correra, A. Del Bianco, and T. P. Lockhart, "Solubility and phase behavior of asphaltenes in hydrocarbon 
media," in Asphaltenes: Fundamentals and Applications, E. Y. Sheu and O. C. Mullins, Eds., pp. 97-130, Plenum Press, 1995.

[15] L. X. Nghiem, D. A. Coombe, and F. Ali, "Compositional simulation of asphaltene deposition and plugging," in Proceedings of the 73rd SPE Annual Technical Conference and Exhibition, SPE 48996, New Orleans, La, USA, 1998.

[16] J. P. Pfeiffer and R. N. J. Saal, "Asphaltic bitumen as colloid system," Journal of Physical Chemistry, vol. 44, no. 2, pp. 139149, 1940.

[17] K. J. Leontaritis and G. A. Mansoori, "Asphaltene flocculation during oil production and processing: a thermodynamic colloidal model," in Proceedings of the SPE International Symposium on Oilfield Chemistry, SPE 16258, San Antonio, Tex, USA, 1987.

[18] G. A. Mansoori, "Modeling of asphaltene and other heavy organic depositions," Journal of Petroleum Science and Engineering, vol. 17, no. 1-2, pp. 101-111, 1997.

[19] H. Rassamdana, B. Dabir, M. Nematy, M. Farhani, and M. Sahimi, "Asphalt flocculation and deposition: I. The onset of precipitation," AIChE Journal, vol. 42, no. 1, pp. 10-22, 1996.

[20] Y. F. Hu and T. M. Guo, "Effect of temperature and molecular weight of n-alkane precipitants on asphaltene precipitation," Fluid Phase Equilibria, vol. 192, no. 1-2, pp. 13-25, 2001.

[21] D. M. Jewell, J. H. Weber, J. W. Bunger, H. Plancher, and D. R. Latham, "Ion-exchange, coordination, and adsorption chromatographic separation of heavy-end petroleum distillates," Analytical Chemistry, vol. 44, no. 8, pp. 1391-1395, 1972.

[22] E. Y. Sheu and O. C. Mullins, Asphaltenes: Fundamentals and Applications, Plenum Press, New York, NY, USA, 1995.

[23] J. G. Speight, The Chemistry and Technology of Petroleum, Marcel Dekker, New York, NY, USA, 1999.

[24] S. I. Andersen and J. G. Speight, "Petroleum resins: separation, character, and role in petroleum," Petroleum Science and Technology, vol. 19, no. 1-2, pp. 1-34, 2001.

[25] J. A. Koots and J. G. Speight, "Relation of petroleum resins to asphaltenes," Fuel, vol. 54, no. 3, pp. 179-184, 1975.

[26] L. Carbognani and J. Espidel, "Characterization of solid deposits from production facilities. Identification of possible causes of deposits formation," Vision Technologica, vol. 3, no. 1, pp. 35-42, 1995.

[27] T. Fan, J. Wang, and J. S. Buckley, "Evaluating crude oils by SARA analysis," in Proceedings of the SPE/DOE Improved Oil Recovery Symposium, SPE 75228, Tulsa, Okla, USA, 2002.

[28] S. F. Alkafeef, A. Fahad, and A. al-Shammari, "Asphaltene remedial technology using advanced deasphalted oil," in Proceedings of the Middle East Oil Show, SPE paper 81750, Bahrain, 2003.

[29] S. F. Alkafeef, F. Al-Medhadi, and A. D. Al-Shammari, "A simplified method to predict and prevent asphaltene deposition in oilwell tubings: field case," SPE Production and Facilities, vol. 20, no. 2, pp. 126-132, 2005.

[30] R. B. De Boer and K. Leeriooyer, "Screening of crude oils for asphalt precipitation," in Proceedings of the SPE European Petroleum Conference, SPE 24987, Cannes, France, 1992.

[31] A. K. M. Jamaluddin, J. Creek, and C. S. Kabir, "Laboratory techniques to measure thermodynamic asphaltene instability," in Proceedings of the SPE Asia Pacific Improved Oil Recovery Conference, SPE 72154, Kuala Lumpur, Malaysia, 2001.

[32] A. Yen, Y. R. Yin, and S. Asomaning, "Evaluating asphaltene inhibitors: laboratory tests and field studies," in Proceedings of the SPE International Symposium on Oilfield Chemistry, SPE 65376, pp. 613-619, Houston, Tex, USA, February 2001.

[33] F. M. Vargas, D. L. Gonzalez, J. L. Creek et al., "Development of a general method for modeling asphaltene stability," Energy and Fuels, vol. 23, no. 3, pp. 1147-1154, 2009.

[34] H. Touba, G. A. Mansoori, and A. M. S. Sarem, "New analytic techniques for petroleum fluid characterization using molar refraction," in Proceedings of the Society of Petroleum Engineers, SPE 38312, Richardson, Tex, USA, 1997.

[35] S. Y. Yang, G. J. Hirasaki, S. Basu, and R. Vaidya, "Statistical analysis on parameters that affect wetting for the crude oil/brine/mica system," Journal of Petroleum Science and Engineering, vol. 33, no. 1-3, pp. 203-215, 2002.

[36] J. S. Buckley and J. Wang, "Crude oil and asphaltene characterization for prediction of wetting alteration," Journal of Petroleum Science and Engineering, vol. 33, no. 1-3, pp. 195202, 2002.

[37] S. D. Taylor, J. Czarnecki, and J. Masliyah, "Refractive index measurements of diluted bitumen solutions," Fuel, vol. 80, no. 14, pp. 2013-2018, 2001.

[38] J. S. Buckley, "Predicting the onset of asphaltene precipitation from refractive index measurements," Energy and Fuels, vol. 13, no. 2, pp. 328-332, 1999.

[39] J. S. Buckley, G. J. Hirasaki, Y. Liu, S. Von Drasek, J. X. Wang, and B. S. Gill, "Asphaltene precipitation and solvent properties of crude oils," Petroleum Science and Technology, vol. 16, no. 34, pp. 251-285, 1998.

[40] L. Goual and A. Firoozabadi, "Measuring asphaltenes and resins, and dipole moment in petroleum fluids," AIChE Journal, vol. 48, no. 11, pp. 2646-2663, 2002.

[41] I. A. Wiehe, "Two-dimensional solubility parameter mapping of heavy oils," Fuel Science and Technology International, vol. 14, no. 1-2, pp. 284-312, 1996.

[42] J. Wand et al., "Experimental and theoretical assessment of the naphalene precipitation characteristics," in Proceedings of the Abu Dhabi International Petroleum Conference, SPE 87292, Abu Dhabi, United Arab Emirates, 2000.

[43] R. P. Feynman, R. B. Leighton, and M. Sands, The Feynman Lectures on Physics, vol. II, Addison-Wesley Publishing, 1989.

[44] K. Vedam and P. Limsuwan, "Piezo- and elasto-optic properties of liquids under high pressure. II. Refractive index vs density," The Journal of Chemical Physics, vol. 69, no. 11, pp. 4772-4778, 1978.

[45] J. S. Buckley, "Microscopic investigation of the onset of asphaltene precipitation," Fuel Science and Technology International, vol. 14, no. 1-2, pp. 55-74, 1996.

[46] N. Aske, Characterization of crude oil components, asphaltene aggregation and emulsion stability by means of near infrared spectroscopy and multivariate analysis, Ph.D. thesis, Norwegian University of Science and Technology, Trondheim, Norway, 2002. 


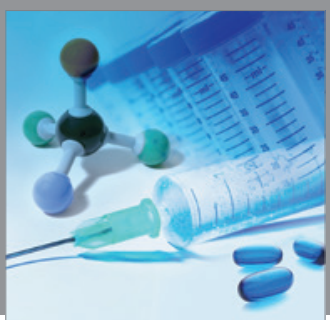

International Journal of

Medicinal Chemistry

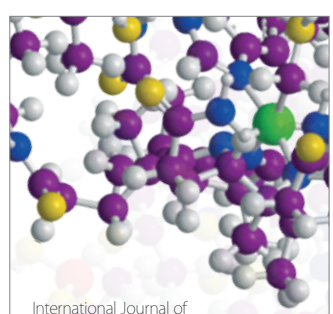

Carbohydrate Chemistry

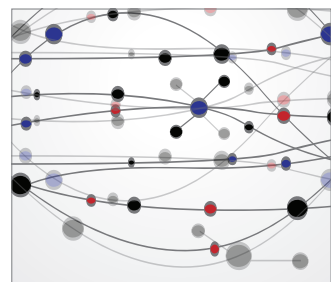

The Scientific World Journal
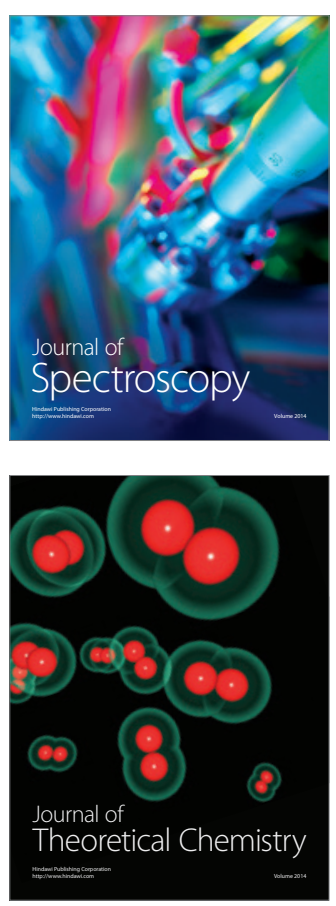
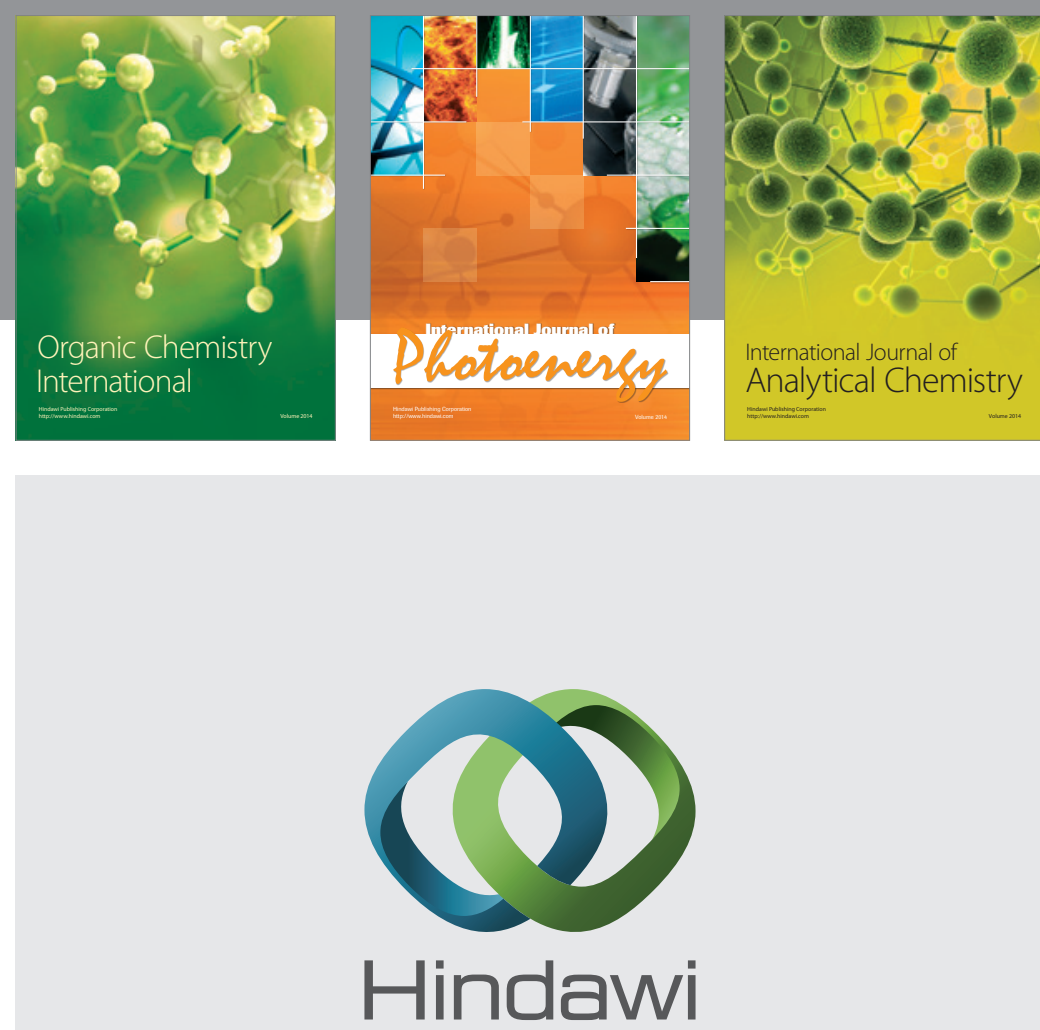

Submit your manuscripts at

http://www.hindawi.com
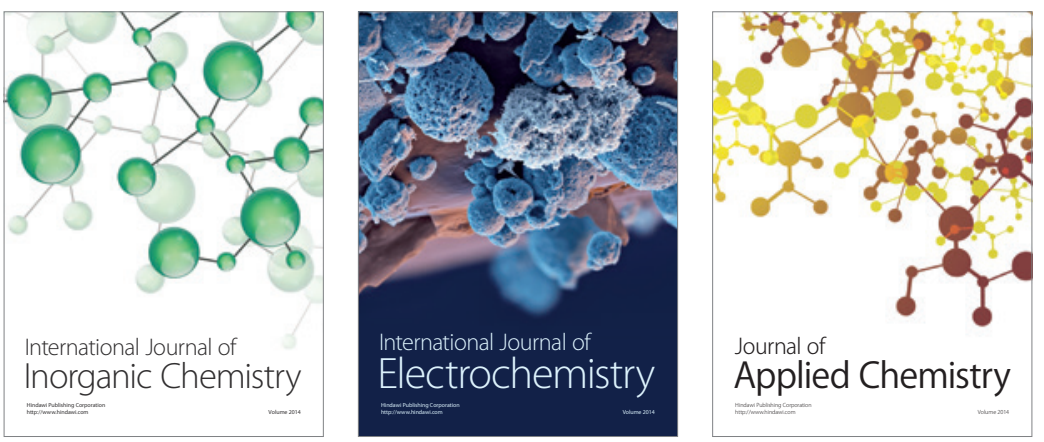

Journal of

Applied Chemistry
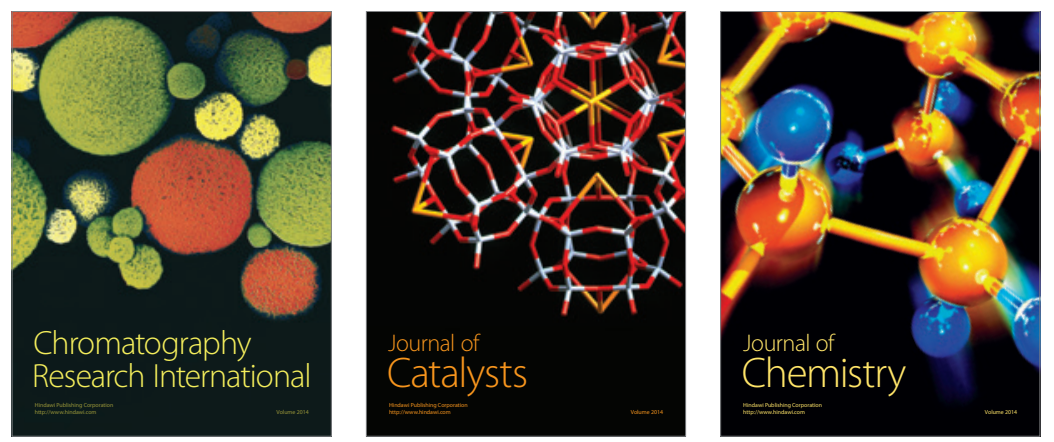
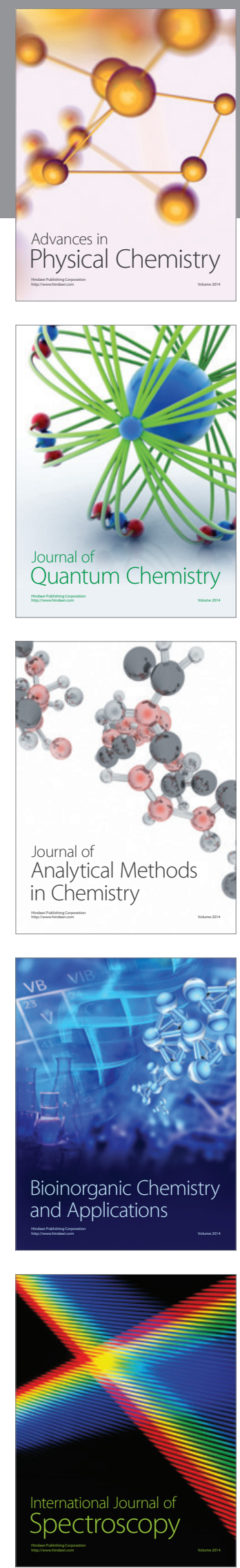